Article

\title{
An Understanding of Religious Doing: A Photovoice Study
}

\author{
Patricia Eyres ${ }^{1, *}$, Katrina Bannigan ${ }^{2}$ and Gayle Letherby ${ }^{1}$ \\ 1 School of Health Professions, Faculty of Health and Human Sciences, University of Plymouth, Devon PL6 \\ 8BH, UK; Gayle.letherby@plymouth.ac.uk \\ 2 Department of Occupational Therapy and Human Nutrition and Dietetics, School of Health and Life \\ Sciences, Glasgow Caledonian University, Scotland G8 0BA, UK; katrina.bannigan@gcu.ac.uk \\ * Correspondence: Patricia.eyres@plymouth.ac.uk
}

Received: 28 February 2019; Accepted: 28 March 2019; Published: 15 April 2019

check for updates

\begin{abstract}
The ability to participate in everyday activities that hold meaning and value is a determinant of health and wellbeing. Occupational therapists work with people when health and social barriers limit this valued participation. However a challenge persists in including religious practice or 'doing' within therapy, with many occupational therapists feeling ill-equipped and reluctant to address religious doing. The study reported here examines religious doing within the lives of participants from a number of faith traditions. A photovoice method is used, with participants discussing photographs that they have taken to describe their religious doing. Data are analyzed using a phenomenological reflective lifeworld approach. Findings are grouped into six themes and are explored using both verbatim quotes from transcripts and some of the photographs taken by participants. A reflective description of the core aspects of participants' practical religious doing is constructed from the data, with the intention of providing occupational therapists with a basis from which to begin to consider practical religious doing within the lives of their clients. It is proposed that occupational therapists do not need an in-depth knowledge of theology and doctrine but rather an understanding of key and familiar occupational principles such as person-centred habits and routines, and community connectedness.
\end{abstract}

Keywords: religious practice; doing; occupational therapy; occupation; participation

\section{Introduction}

Recent research suggests $84 \%$ of the global population identify with a religious group (Pew Research Center 2015) and, as such, it can be argued that religious practice is an everyday or regular activity for many people. But from an 'activity' view point what does the term religious practice actually mean? It is a commonly used term, however Jones (2004) discusses the limitations of language when trying to understand the essence of religion and asserts that 'religious doing' is in many ways a more helpful term than 'religious practice'. For many people religious doing forms part of very many varied and complex 'doings' that make up their daily lives. Within a healthcare context, the doing of everyday activities, their facilitation and adaptation, as needed, is the domain of occupational therapists, who believe that within daily life, a relationship exists between what we do, and our sense of self, our identity and our experience of health and wellbeing (Wilcock 1999). The place of spirituality within healthcare practice has been explored across many disciplines (Swinton and Pattison 2010), and definitions of spirituality often encompass religious concepts such as a connection with a divine presence and the practice of ceremony and ritual (Unruh et al. 2002; Johnson and Mayers 2005). From a health promotion view point religious practice has been linked to health outcomes, on the basis that 
people who belong to faith communities are likely to drink and smoke less and are less likely to engage in risky sexual behaviours (Koenig 2011).

Within the field of occupational therapy there has, however, been an emphasis on spirituality, at the expense of a clear understanding of 'religious doing' as a spiritual component of many peoples everyday lives. For the occupational therapist, activities and tasks (doing) become 'occupations' when the person performing them considers them meaningful—for some people this includes activities related to their religion or beliefs-in a practical sense their religious doing. The fields of practical theology, psychology of religion, and sociology, contain much information to broaden our knowledge of religious doing. The term religiosity is used and recently defined by Schuurmans-Stekhoven (2019) as

A personal dedication to culturally-venerated beliefs in a higher immaterial realm ... a reverence for certain claims regarding the existence of unverifiable mystical forces and a personal identification with sacred texts, symbols/sites, practices and rituals (p. 129).

Concepts of practice and participation are explored within religiosity and link to the occupational concept of 'doing'. However for occupational therapists and occupational scientists 'doing' sits within a structure of doing, being, becoming, and belonging (Wilcock 1999), with these aspects of occupational performance being linked to wellbeing. While the psychological or sociological aspects of religiosity may be helpful to aid occupational therapists' understanding, an occupationally structured understanding that focusses on 'doing' will enable occupational therapists to better comprehend religious practice as just another valued occupation. It is not something that sits outside of their practice remit. As activities related to a patient's religion are rarely considered as part of intervention, a truly person-centred focus, which is a key element of the therapeutic relationship, is in danger of being limited. With this in mind, this paper considers religious doing from an occupational perspective and explores the practical aspects of some people's everyday engagement with their religion, across faiths. Our objective is to produce a 'lived' reflective description of participants' religious doing, which both contributes to practical theology and, in addition, is aimed at helping occupational therapists to consider religious doing in practice, when this forms part of their clients' valued occupations.

Within occupational therapy the term 'occupation' refers to everything people are engaged in on a day-to-day basis that gives meaning and purpose to their lives (Wilcock 1999). The view that occupation is inextricably linked to wellbeing underpins occupational therapy and the associated field of occupational science. Occupational science explores the nature of occupation itself to enhance understanding and thus enable the therapeutic use of occupation within therapy. The study reported here is part of series of studies in occupational science and was undertaken recognising that currently occupational therapists struggle to include religious practice as an area of everyday activity within intervention (Thompson et al. 2018). A number of previous studies report barriers (Wilding et al. 2005; Bursell and Mayers 2010; Thompson et al. 2018) and suggest that occupational therapists feel ill-equipped to focus on religious practice, that knowledge and understanding of this activity is often limited, and that religious practice that falls outside of a practitioner's own experience and culture is particularly challenging.

Wilcock (2007) proposed the need for basic occupation itself to be fully explored and understood before issues of 'application' in a practical and therapeutic context can be addressed. This emphasis on the understanding of the nature of occupations is a core concept of occupational science and the study reported here therefore aims to explore the practical religious doing of people from a range of faith traditions, seeking a broader understanding of their practical engagement.

\section{Background Literature}

Hocking (2009) suggests a number of key areas that should be considered when investigating any occupation valued by a person, and, when considering activities related to someone's religion, the areas to explore are potentially vast. For example, to name a few, meditative skills and the ability to read in a second language; stereotypes and tolerance of different sects; the rules of participation in 
ritual and ceremony and who is making and interpreting those rules; place and the possible desire for a numinous environment; frequency of participation and the significance of seasonal celebrations.

In relation to religious doing in the context of occupational therapy and occupational science, the literature is limited. Farah and McColl (2008) explored prayer as a spiritual modality, within therapy, by conducting a literature review. They concluded that engagement in this religious occupation can be seen as positive, in terms of meeting the needs of the client, allowing a therapist who practices a religion to be 'true' to their beliefs, strengthening the therapeutic relationship, and potentially aiding healing. However, they also suggest some more negative issues, with the possibility that prayer may be interpreted as coercion (jeopardising the therapeutic relationship), that there is a potential for role confusion, a lack of training, and a lack of support from employers. Smith-Gabai and Ludwig (2011) provided a descriptive and informative account, having observed the Jewish Sabbath. They detailed Jewish ritual, including prayer, meals/food, attendance at the synagogue and the need for 'rest', defined as a day without work. Beagan and Etowa (2011) explored the spiritual occupations of African Nova Scotian Women in Canada. Fifty women in this study expressed spiritual occupations that provided connection to church, to community and to God; supported them with moral guidance and direction; and helped to re-frame health challenges (Beagan and Etowa 2011, p. 288). Smith and Suto (2012) worked with 11 co-researchers, who all had a diagnosis of schizophrenia. Using semi-structured interviews they concluded that agency (choice and autonomy) was particularly important within this group's view of religious practice. Courtney (2013) explored the literature concerning pilgrimage encompassing, but not limited to, a form of sacred travel that is of great personal significance. With the exception of Courtney (2013) this literature only explores a Judeo/Christian view of religious doing and does not address the wider needs or perspectives of people from other faith traditions. For occupational therapists working in increasingly multi-cultural and multi-faith communities, information that is only relevant to Judeo/Christian perspectives is limited.

The occupationally focussed literature concerning religious doing, such as described above, is rarely found and has therefore played a limited role in the wider debate about spirituality within occupational science and occupational therapy. The reluctance of occupational therapists to address this area of activity with their clients persists, and there is a need for a broader understanding of the everyday aspects of religious doing, a greater confidence in its inclusion, and a wider multi-faith perspective. An holistic person centred approach cannot be the basis for intervention if an important aspect of a person's identity and occupational life is omitted. Occupation is both a means and an end (Fisher 2013) and therefore, by exploring religious doing, occupational therapists can utilise aspects of this doing within therapeutic goals while being truly person centred in the collaborative objectives agreed with their clients.

\section{Methodology}

The research reported here forms part of a series of studies using a facet approach (Mason 2011) with the overall aim to explore religious practice as a valued occupation. The study reported here adopted a qualitative phenomenological approach (Finlay 2011), which seeks to understand the lived experience of a phenomenon, in this instance religious doing. Phenomenology typically uses small sample sizes, as data saturation is irrelevant (Van Manen et al. 2016), where an understanding of individual lived experience is the objective. Quantifiable and generalizable conclusions are not the objective however there is potential for an exploration into individual experiences to offer insights into, and understanding of, the human condition (Finlay 2011, p. 10). However the deeply personal nature of religious doing presents a challenge in obtaining rich data. Commonly used data gathering techniques such as semi-structured interviews or focus groups can have some limitations when exploring highly personal and private subject areas. For example people may seek to give the response they perceive as expected, they may struggle to reflect deeply, and may be wary of upsetting or disagreeing with other participants (Gray 2004). A complementary and creative alternative means of expression to support 
the collection of rich data was sought (Hartman et al. 2011; Mason and Davies 2009) and photovoice was chosen as a suitable data collection method.

\subsection{Photovoice}

This participatory photography method (Wang and Burris 1997) is an active and creative technique that gives individuals an opportunity to both record and reflect on their daily lives (Lal et al. 2012). This technique has frequently been modified for research purposes (Catalani and Minkler 2010), and is more descriptively called participatory photographic interview (Warren 2005), where participants are asked to take photographs of their lived experience and talk about these images with the researcher. As the aim here was to explore the lived experience of people from a range of faith traditions, this technique offered an accessible means for people to capture their own experiences and the photographic record promoted more in-depth reflection and discussion than interviews alone could have elicited. Participants were asked to capture their own personal religious practice, not necessarily typical religious practice, and because this was done without the direct influence of us as researchers or our physical presence, control was passed to the participant. While some degree of 'conformity' i.e., photographing what the participant perceives as expected, is always possible, there is evidence to suggest that the photovoice approach reduces this considerably (Blackman 2007; Lal et al. 2012).

Cultural, and lifestyle diversity, often seen as a problematic complexity within photovoice studies (Hartman et al. 2011), was actively sought in the study reported here, to enable a cross-faith perspective (Darnell 2002; Iwama 2003; Odawara 2005) and reflect the multi-faith nature of 21st century communities. Ethical approval was granted by the University of Plymouth Research Ethics committee (Ref 2/134-123) for participants 16 years and over, and provision was made for parental consent should anyone aged between $16-18$ years have volunteered.

\subsection{Recruitment and Data Collection}

In order to access a wide range of potential participants from a breadth of faith traditions, in line with the aim of the study, the recruitment was conducted in partnership with two multi-faith centres and a university multi-faith Chaplaincy (all located in the south west of the UK). Potential participants were invited to take part via postings on on-line notice boards and newsletters. Two information meetings were held for anyone interested and in addition some basic instruction on the use of a digital camera was offered. Participants were able to use their own camera or a disposable camera was provided. In total 10 participants (five male and five female) were recruited with ages ranging from 33-80 years old. Seven faith groups were represented; Baha'i, Buddhist, Christian, Hindu, Jewish, Muslim, and Pagan (see Table 1).

Table 1. A summary of participants' characteristics.

\begin{tabular}{cccc}
\hline Pseudonym & Faith Group & Sex & Age \\
\hline Jac & Pagan & M & 80 \\
Anne & Baha'i & F & 50 \\
Zaheem & Muslim & M & 37 \\
Rachel & Jewish & F & 47 \\
Beth & Christian & F & 55 \\
Mark & Buddhist & M & 59 \\
Penny & Christian & F & 56 \\
Sanjit & Hindu & M & 36 \\
Arif & Muslim & M & 35 \\
Jen & Christian & F & 33 \\
\hline
\end{tabular}

All participants received written project information and all participants signed consent forms agreeing to take part in the study. Particular attention was given to informed consent. In addition to consenting to participate, it was made clear that photographs taken would remain the participants' 
own property, and a further discussion about consent to use any photograph within the research, formed a second round of consent. This was necessary as truly informed consent can only be given in relation to an image once that image actually exists (Blackman 2007). Participants were asked to take photographs that they felt expressed their religious practice. Some discussion about the nature of images was undertaken in the groups at the information meetings i.e., the documentary nature of an image and the more abstract possibilities to represent thoughts and feelings. However, we were careful not to specify or suggest any particular type of image and encouraged participants to take photographs of anything they felt relevant. No specific time frame was set at the beginning and participants were asked to contact us when they felt they had captured the images they wanted to take. Follow-up phone calls were made a few weeks in, to check on their progress and maintain contact. Interviews were scheduled based on the participants stating that they had finished taking photographs.

Each participant was interviewed individually about the photographs they had taken. Interviews were unstructured with the discussion starting with a single question; 'Can you tell me about the photos you have taken?' The rationale for an unstructured approach was to ensure that the photographs themselves directed the discussion and that the reflections offered were truly person centred and not pre-determined or influenced by the researcher. Each interview was audio recorded and subsequently transcribed verbatim. Participants took between two weeks and four months to take photographs and the number of photographs included in the interviews ranged from two to 25 . The only other pre-determined question asked was: if there was a photograph that the person would have liked to have taken, but for some reason was unable to (Blackman 2007). This is often termed the 'missing photograph' in photovoice interviews. This gave the participants an opportunity to explore any further aspect of their experience that had not already been discussed and contributed to the inclusiveness of this technique (Hartman et al. 2011).

\subsection{Data Analysis}

Within the photovoice technique, a thematic analysis (Nowell et al. 2017) of the transcribed interviews is commonly undertaken however, in the study presented here, Dahlberg's (2006) Reflective Lifeworld research approach was used. This approach was applicable here because it focusses on the everyday taken-for-granted meanings around us. In this approach, analysis includes the search for descriptive themes emerging from the data, but also requires active but 'bridled' reflection from researchers, and the use of images to deepen insight. Researchers are required to 'bridle' their pre-existing beliefs and knowledge: to rein in pre-suppositions and their own lived experience. This is a more realistic and reflexive approach than the more commonly used 'bracketing' used within phenomenology which requires researchers to completely separate their previous experience and look at the data beyond preconceptions (Tufford and Newman 2010). The Reflective Lifeworld approach allowed for the researcher's (PE's) own reflective interaction with the data, as a practicing Christian, and also encompassed the contribution of the images created by the participants. As part of analysis a reflective consideration was given to the data which was further influenced by the concept of 'theorised subjectivity' (Letherby et al. 2013). This concept argues that it is necessary for us to make a very careful consideration of the significance of subjectivity in our pursuit of objectivity. The researcher (PE) tried to both acknowledge her own faith position and accept that, while an honest and clear interpretation of the data was always her objective, nevertheless she could not suddenly become a non-Christian or someone who is unconcerned about the problems of including religious doing within occupational therapy practice.

Initial codes were generated with the researcher's own experiences 'bridled'; that is 'held back'. However, after this initial phase, reflections on her own lived experience of religious doing were used to aid further analysis, and ultimately contribute to the themes generated. Dahlberg's (2006) approach calls for descriptive themes but in addition these were further categorised into intrinsic and extrinsic themes (Braun and Clark 2006) to further structure the analysis and discussion. The Reflective Lifeworld approach is aimed at exploring the lived experiences of participants from varied and diverse 
perspectives, including the perspective of the researcher, and is therefore applicable to the overall aim of the research reported here. Analysis are brought together inductively (Guest et al. 2012) culminating in a reflective description of religious doing within the everyday lives of the participants.

\section{Findings}

The search for descriptive themes initially involved dwelling with the data (reading and listening to the interviews) which generated 85 codes. Reflective notes were added to the codes and together codes and reflections were grouped into themes. PE's initial grouping of codes (from a bridled position) did not make the clear categorization of intrinsic and extrinsic themes, however after reflecting on the codes from her own Christian perspective (non-bridled position) a differentiation emerged between observable doing and the meanings associated with doing. The Reflective Lifeworld approach suggests both a bridled and non-bridled consideration of the data are used but that, additionally, a creative analysis should also be used wherever possible. In this instance the photographs were then considered and helped to re-group and refine the themes particularly in relation to how place and use of space were considered. Finally codes were grouped into six overarching themes. Two themes considered extrinsic (largely observable) features, termed by Braun and Clark (2006) as manifest themes dealing with description, and four intrinsic features, termed as latent themes, considered aspects relating to meaning (see Table 2).

Table 2. A summary of themes identified within the participants' descriptions of their religious doing.

\begin{tabular}{ll}
\hline Extrinsic features & $\begin{array}{l}\text { The structure and rules of practice } \\
\text { Expressions of practice }\end{array}$ \\
\hline & The impact of capacity and time \\
& Relationship with the divine \\
Intrinsic features & Experience of Connectedness \\
& Worldview \\
\hline
\end{tabular}

These themes are now discussed and, in addition to participants' words, some of the photographs taken are used to both illustrate themes and offer additional depth.

\subsection{The Structure and Rules of Practice}

Religious practice was described as being within a framework or structure that includes aspects of ritual, place and laid down rules or governance. Participants talked about 'proper' or correct practice and some issues that present challenges to correct practice.

There are obligatory prayers and you should be praying three times a day using obligatory prayers (Anne).

Diwali is a celebration of light. It is also the beginning of the New year so people do a lot of-er-spring cleaning around that time (Sanjit).

One of the very good things is actually the rule ... the start of the Sabbath on a Friday ... is actually you stop work (Rachel).

During the fasting month then ... then everyone does make an effort to try to pray in a group, we're supposed to ... its important (Zaheem).

Structure was articulated in terms of routine and ritual and was positioned within what was seen as 'normal practice', and how the individual's practice was measured against this norm. All participants expressed an underlying concept that practice was 'organised' and visible in some way although, as a religious practitioner, it was also possible to deviate from this organised structure. The individuality of religious doing was a feature throughout the interviews with participants discussing their own practice 
in relation to a perceived 'norm'. Structure invariably included the notion of a standard that should be adhered to. On occasions participants felt they struggled to measure up to a required standard expressed by statements such as 'you're supposed to go regularly but I don't' (Jen) or 'I should stop during the day but I don't always remember' (Rachel). There was also acknowledgement that a religion had a set of rules or doctrine that provided guidance for religious doing. This aligns with Hocking's (2009) view that we need to understand the standards by which an occupation is judged and the rules of participation, before we can consider its inclusion within the therapeutic context.

Judaism may have like a million set of rules for lots of different reasons at lots of different times, (... ) but actually kind of give you a baseline and a code (Rachel).

However, the guidance available was not always considered helpful and at times may be challenging.

the church as a whole is not necessarily going to give the guidance I want to hear-is that me who's wrong or the church who's wrong or am I not hearing what God is saying —and I can't believe that (Penny).

There was also wide acceptance that 'normal religious doing' could take various forms and that variations in practice were commonplace and not an issue, with tolerance frequently expressed. Participants discussed different 'varieties' of a religion and different sects and alternative practices. Mark talked about being a Zen Buddhist and that this is only one type of Buddhism. Jen said she was a 'let go, relaxed Christian' and implied that this was not the case for every Christian, while Arif and Zaheem both talked about varying ways that Muslims interpreted the way ablutions needed to be performed before prayer. This suggests that although the personal nature of religious doing has potentially limitless variation it is articulated as being positioned within the 'public' structure of religion. Practice would appear to be positioned within a concept of what is proper, legitimate and expected practice but also what is personally acceptable to the practitioner.

\subsubsection{Ritual}

Ritual practice was discussed in every interview. Ritual was described as patterned behaviour that again was determined within the rules set down by a faith group. Ritual was expressed as 'comfortable' engagement, where participants felt they understood what they should do and the significance of the acts they were performing. The visible and observable nature of practice was included by everyone but, where ritual practice occurred, was often not directly related to place. At the same time there was an acknowledgement that a designated place for ritual to take place, contributed to the structure of practice and contributed to a feeling of connectedness. Very few photographs were taken of the participants' own/regular place of worship. These images were identified by some people as the 'photo not taken' due to ethical considerations and the appropriateness of using a camera during a ceremony or worship. In some instances a lack of designated site or place was also highlighted and this appeared to raise the significance of other aspects of ritual practice, for example, when describing offerings as part of Diwali celebrations...

On its own [offerings] has got quite a significant aura about how we pray, ( . . ) especially when we don't have a temple (Sanjit).

Overall the structure of practice relating to organised forms, ritual, and place was suggested as a key part of defining practice from the everyday perspective of the participants.

\subsubsection{Challenges}

Legitimate, or proper, practice was seen as challenging under certain circumstances. For the Muslim participants in particular the availability of appropriate facilities for ablution was a particular issue. Ablution practice was adapted by Zaheem to include the use of 'wet wipes' (see Figure 1) and 
Arif described being able to use the facilities to hand but not without hazard and some strange looks from anyone who observed him preparing for prayer in the men's toilet (see Figure 2).

I'm really short so I sort of I need to hold my legs in a dangerous manner and the thing is we need to wash both of our feet so sometimes when I begin with my right foot that's why-but where I put up and my left foot and wash, my right foot is slippery and I might fall a couple of times cos its slippery (Arif).

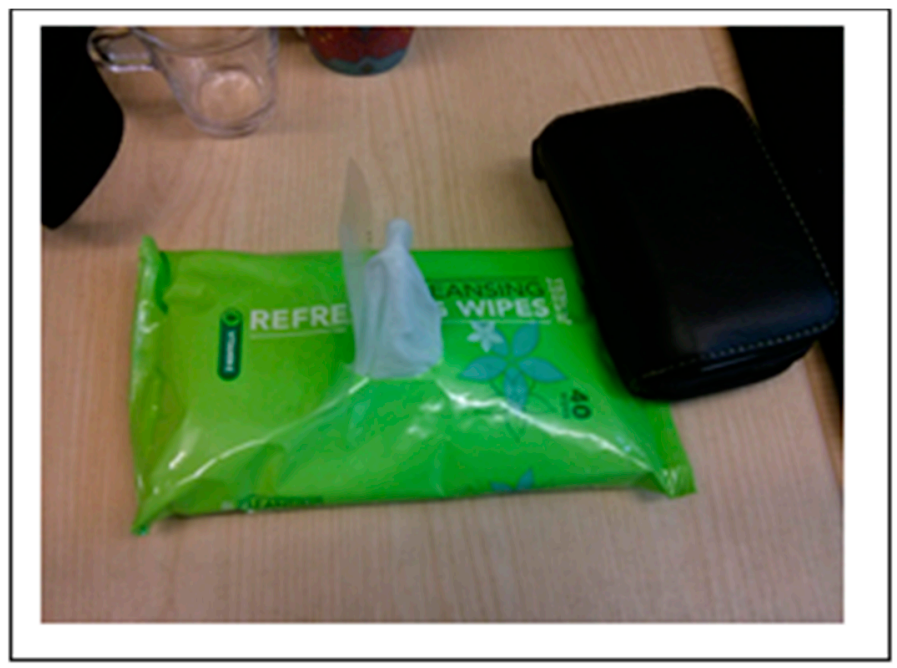

Figure 1. Photograph taken by Zaheem of wet wipes used to 'wash' before prayer.

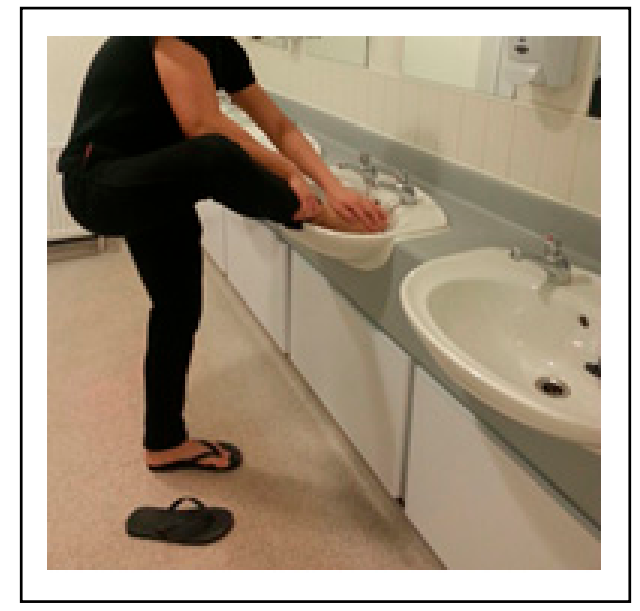

Figure 2. Photograph taken by Arif's friend of his ablutions.

\subsection{Expressions of Practice}

The second of the extrinsic themes relates to how participants expressed their religious affiliation openly to those around them. Significant objects were frequently photographed and images of symbols, sacred texts and literature were used by participants to describe their expressions of faith. In some cases a special place had been created for important items.

This is a shelf on a whole series of shelves in one of the rooms. Um, so, I walk past it every day. So, it's just visible to me. Um, and the items are very special to me (Beth) (see Figure 3). 


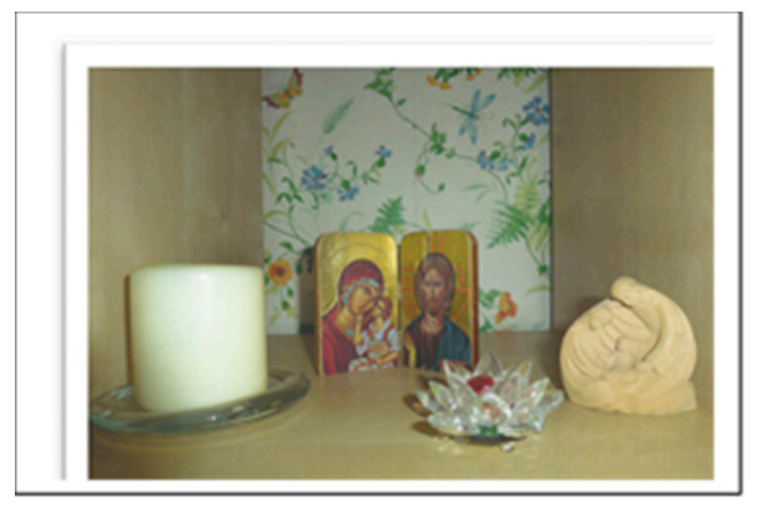

Figure 3. Photograph taken by Beth of her 'shelf'.

And for Anne, the significance of an object (her prayer book) also included its tactile nature.

I bought this prayer book-it's a really nice prayer book. Its leather bound and for me that's kind of important because it's quite tactile and I like the feel of it (Anne).

Symbol

Expressions of practice also included the use of symbols, as something commonly worn, found about the house or otherwise used within ritual, ceremony or worship.

I tend to have more um, like sayings from the bible in a bookmark or these palm crosses around just to remind me of what Jesus did for us (Jen).

Sanjit (who did some voluntary work in schools) felt it important to use the Hindu symbol for 'home' on presentations, as concepts of family and home are so central to the Hindu religion, even though few people other than him realised the significance of this symbol.

'and a lot of our world starts with the symbol 'home' (Sanjit).

Jac described the symbolism of his ring (see Figure 4) and a stone worn around his neck.

They're called hag stones and to me they relate again to the Goddess. So I think this is why this is important one, a stone with a hole in it. And uh, not all pagans wear them, but quite a lot do. We're loaded up with symbols, absolutely. We use them a lot (Jac).

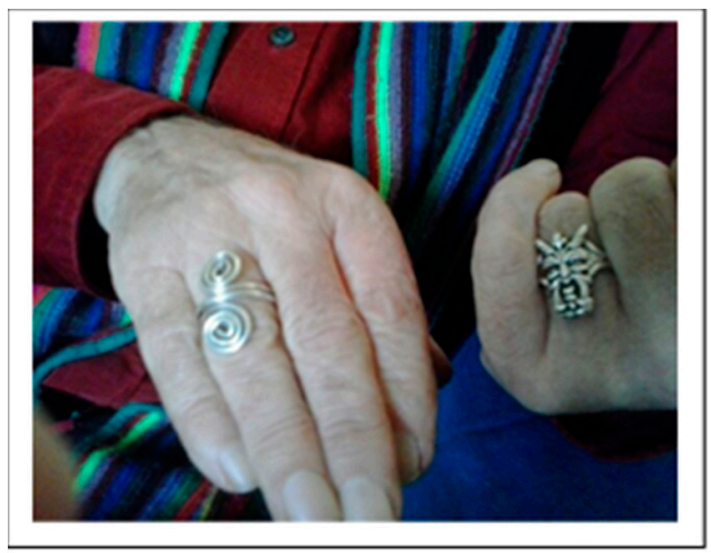

Figure 4. Photograph taken by Jac's friend of his symbolic jewellery. 
However, Anne was cautious about wearing a symbol that demonstrated an outward expression of her practice.

And this is a necklace which is, again, the symbol of Baha'i which means splendour. And I don't wear it all the time I have to say. And there are some times when I-because, again, it's sort of our-it's Persian calligraphy, but it looks like Arabic. One of the reasons I don't wear it is because I'm concerned about discrimination from people (Anne).

This would suggest that the use of symbols is contextual-some places and occasions are both safe and appropriate to use symbols but others are not (Stewart et al. 2018). An outward expression of one's membership of a faith group was seen as largely desirable but there was also potential for risk in certain cultural and social situations.

The following themes are more intrinsically orientated but again were found across faith traditions.

\subsection{Impact of Capacity and Time}

The amount of time that practice is likely to take and how this might fit into a regular routine was captured within the data. Arif and Zaheem, and to a lesser extent Anne, spoke of a structured prayer ritual which punctuated their daily routine. Others talked about routine in terms of weekly practice or more periodic practice; a weekly bible study for mums with young children (Jen), attending Sunday services (Penny), Friday prayers as being a particular 'focus of the week' (Zaheem) and the Friday Sabbath meal as being a point in the week that you could always 'count on' (Rachel). In addition participants felt 'making time' was an important aspect of practice.

The prayer itself, you know, is two to five minutes. It doesn't take very long so it's-it's certainly doable (Arif).

The issue of time was also picked up by participants who discussed the adaptable nature of their practice - so that it was possible to catch up on missed religious doing.

I have to by-pass that midday prayers so in Islam if you like sort of by-pass that midday prayer ... its

OK as long as you ... er ... replace it by doing the same prayer at a different time ... yeah (Zaheem).

In general, a pragmatic approach to adapting practice was reported. Participants altered or adapted their doing to best fit with their situation. Life roles also impacted on religious doing both in terms of how time was used and what aspects of other roles contributed to religious practice. Sanjit, who taught basic cooking skills to users of a local food-bank, saw this as a time spent expressing his Hindu core principles. Penny, a music librarian, considered music as integral to her practice, while Jen, a mother of small children, discussed her role as a parent and the need for her practice to be 'child friendly'.

Several participants also highlighted that their practice changed over time and was seen as different at different points in the life-course. Several people talked about aspects of practice that they had experienced as children, or as younger people, and generally saw their practice as developing over time.

And I know in life we go through times when our spiritual life changes and I need, you know, we need to find something different, a different way of doing things (Beth).

Lastly, there was discussion about religious doing as being part of life that was in itself part of a much bigger 'process'. Clearly, doctrine and beliefs differ between the faiths represented in the study, however there was overall a sense that beliefs positioned one within a continuum that spanned time, and that time was bigger than one's own lifetime.

I can't look at a new-born or a young baby and not see God. It's something about eternity (Beth). 


\subsection{Relationship with the Divine}

A further aspect of practice was discussed in terms of a dialogue with the divine or other. The terms used here varied, i.e., contemplation, prayer, meditation, mindfulness, but there was a personal need for a relationship with the divine whether or not that was through organised and structured practice or very personal 'quiet' practice.

It's important-my own conversations with what I assume to be God (Penny).

And I guess prayer is not something that you talk about, some of it is kind of about just what you're doing — is a pattern and a way of doing things (Rachel).

Little moments of where you got these little sort of like no-self moments um, which you are reminded of the uh, of the um, transient nature of the self (Mark).

Spending time in contemplation or prayer, where there was an opportunity to focus on a particular issue, was frequently expressed as important. In addition there was a concept that it was necessary to lose oneself within this process, potentially linking to the concept of flow (Reid 2011). Peace and tranquillity were important aspects of time spent in personal contemplation and a quiet place to pray was seen as facilitating and often sought out purposefully.

I think places like this that are peaceful and you can see God's glory and it's overlooking, you know, water and hills and everything, um, it is a peaceful place to be with God (Jen) (see Figure 5).

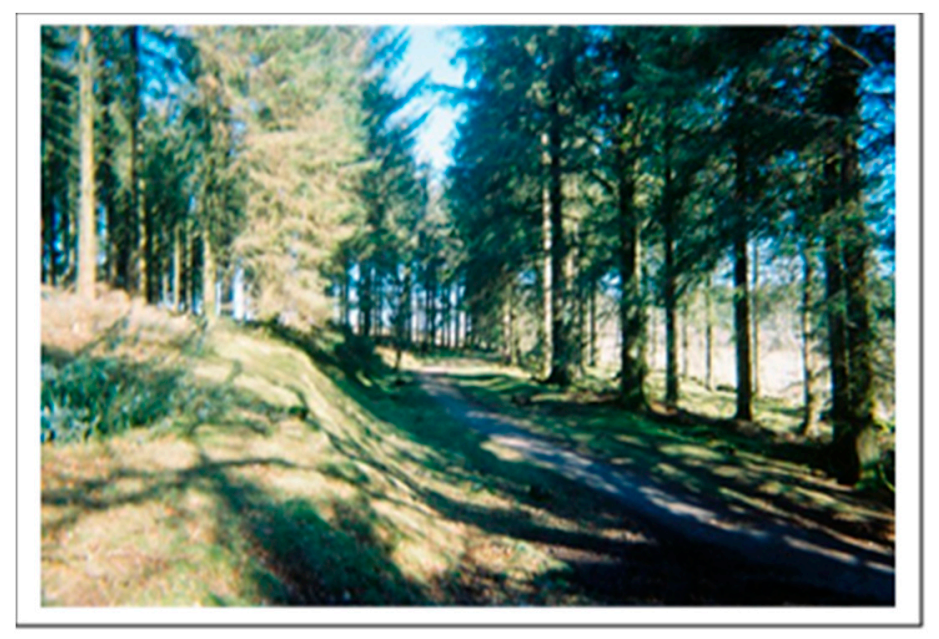

Figure 5. Photograph taken by Jen of her favourite peaceful place.

From a 'doing' point of view prayer was on occasions seen as something that could be done while engaging in another occupation.

And indeed I pray when I'm on my feet. When I'm out in town and I see people. I send them a prayer,

I ask God to bless them (Jac).

Personal dialogue with the divine was also seen as an opportunity to question and debate beliefs and practice, but overall having a relationship with the divine was seen as needing space but also enabling the creation of peace and tranquillity within busy everyday life. Several participants saw the natural world as an important expression of a 'creator' and, as such, being close to, or having time to experience, the natural world was seen as an important aspect of a relationship with the divine. The photographs taken by participants often included an expression of nature and the discussion about these images included the notion that 'nature' helped the sense of connectedness or 'being near God'. 
But there was something about the light um, and that sort of sense of-I think there's something about the word awe in nature, you know, that sense of um, the light breaking through the clouds and there's a sense for me, very often that evokes a sense of God (Beth) (see Figure 6).

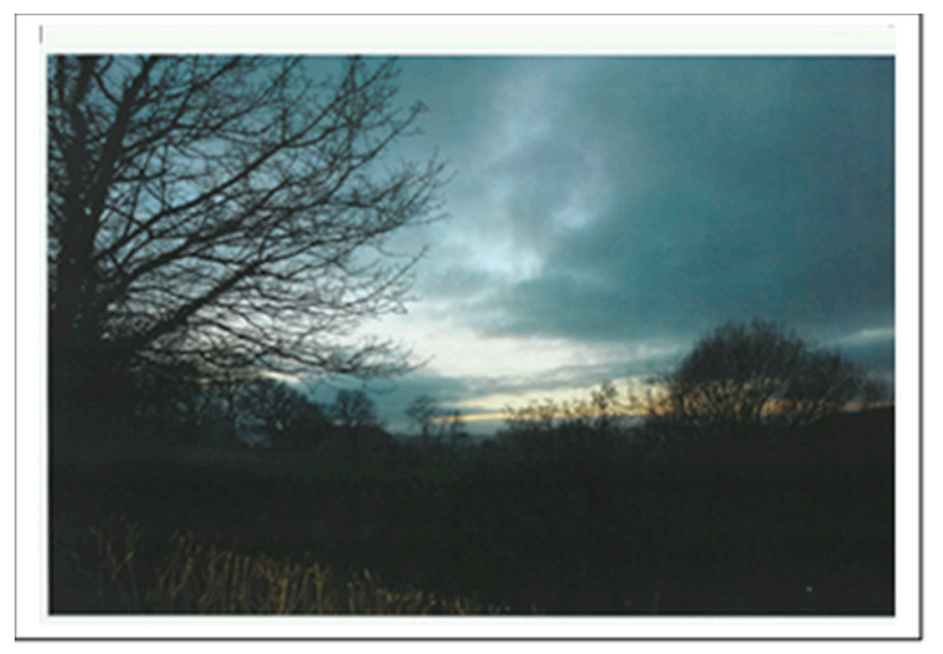

Figure 6. Photograph taken by Beth of the sun breaking through clouds.

A relationship with the divine was, understandably, articulated as a very personal aspect of religious doing. The meaning of this relationship related to doctrine and belief however there were common features of this aspect of religious practice that included the need for peaceful space and place, making time within a busy day and often having a connection with the natural world.

\subsection{Experience of Connectedness}

All participants discussed religious doing with others and the notion that practice was both an individual but also a collective activity (Pickens and Pizur-Barnekow 2009). Participants discussed practice with a group of others as being of particular significance and something that was 'missed' when not available. Missed aspects of practice or a lack of opportunity were expressed in terms of sadness or regret and directly linked to the availability of community and/or fellowship. Religious groups that are in a minority may 'miss' wider opportunities for fellowship and connection due to their small numbers. This was expressed by Zaheem who, when speaking about a large and spacious Mosque he had experienced as a child, commented 'I particularly miss that'.

The social aspects of being part of a faith group were also discussed with the inclusion of food on occasions and an opportunity to 'be with friends'. Being part of a community was seen as helping one's own development of practice.

your own faith is nurtured by the ways in which you grow to care about other people's faith life and other people generally — sort of through the community (Penny).

Community and fellowship were discussed in terms of being with people who had a common understanding or worldview. In addition there was a notion that it was important for groups to be welcoming and 'open' to anyone who may want to join with any aspect of practice.

I think about the groups and how society is becoming more secular, and faith for me is about being very open and um, welcoming (Rachel).

Experience of connectedness with others and relationships with other significant people, especially within the family, was also a feature of the data. Notions such as, educating one's children in aspects of religious doing; that home and family life were important expressions of religious doing; that other people could inspire practice but also that one's own religious doing may influence others. 
It's amazing how people can be a window to faith for other people (Beth).

On occasions practice was discussed within the concept of lost connectedness or community, and this was more apparent in groups that may be considered minority groups (at least within the geographic location of the study presented here in the UK). Occupational therapists increasingly work with minority and/or marginalised communities and an understanding of connectedness as a feature of valued occupations is key in these areas of practice (Creek and Cook 2017).

\subsection{Worldview}

Participants were clear to orientate their practice within a worldview that was invariably linked to the doctrine and beliefs of their faith. A way of viewing the world that helped them to understand the world, and consider their place within the world. The concept of 'sharing' and a 'respect' for others' beliefs was a feature of the data. As most participants were recruited via inter-faith organisations this view of tolerance and inclusion is somewhat predictable, and may be skewed from the general view of other members of religious groups.

How to relate to other people and live a life that demonstrated your faith were frequent themes within the narratives. Culture was seen to impact on this and again participants from groups that may be viewed as a minority, were anxious to express their worldview as sitting within, and tolerant of, a UK (arguably) Christian culture. A diversity and mix of religions was seen as both a positive aspect to society but also as causing some degree of chaos and challenge. In addition the concept of culture was, for some participants, difficult to separate from their religion; with religion, culture and race being complex and intertwined concepts.

the whole concept of actually faith and race. We're all parts of different mix-ups of that, there isn't actually one thing that is particularly you, it's the jigsaw that makes up your life (Rachel).

Participants expressed their religious practice as providing them with a particular way to view the world around them-a lens through which to view the world but also a lens through which the world could view them.

\section{Reflexive Bridling}

As already outlined, analysis involved a reflective and reflexive consideration of the data and this contributed to the themes discussed above. The Reflective Lifeworld approach was chosen to acknowledge the first author's (data collector) ( $\left.\mathrm{PE}^{\prime} \mathrm{s}\right)$ own faith and her own interaction with the data. Initial codes were generated with her own experiences 'bridled', that is 'held back', however this approach embraces the notion that this can only be done partially and that once initial codes have been generated then one's own lived experience should be used to further aid analysis and contribute to the themes developed and discussed. Bridling is rarely however a single 'event'. Inevitably the researcher moves backwards and forwards between objectivity and subjectivity within the concept that these are in reality inseparable (Dahlberg and Dahlberg 2019). For example, PE initially found that the language she used for codes had a Christian orientation i.e., the term fellowship. In attempting a more bridled approach and seeking a more neutral or multi-faith language this became 'connectedness'. After the initial themes were formulated this was again reflected on to ensure this was suitable language to encompass all the perspectives represented in the data. Some direct comparison between different faiths was of course possible but the aim here was to explore the practical religious doing of people from a range of faith traditions, seeking a broader understanding of their practical engagement, and not to simply identify comparisons. To do this the Reflective Lifeworld approach suggests that analysis may culminate in a reflective description of the phenomenon being explored, in this instance the religious doing within the everyday lives of the participants, illuminating variable meanings from the data, embracing those variations and highlighting common features (Dahlberg 2006). 


\section{Further Discussion}

The data here contains descriptive information about the religious doing of the participants with common themes emerging across the faith groups represented. How religious doing is measured against a perceived norm featured prominently in participants' narratives and participants were often self-critical of their own practice. A desire to 'do better' was as present here as it is in many occupations (Hocking 2009). Routine and familiarity also featured prominently-a feeling of being comfortable, regularly engaging in familiar practice in a familiar place-what Kielhofner (2008) defines as the habitual aspect of doing.

Quiet time spent in contemplation was also important but this was not just about a quiet space, in the physical sense, and more about making time and space within the participant's thoughts and cognitive priorities. Many of the descriptions of contemplative 'doing' had elements of flow, i.e., being less aware of one's surroundings and losing a sense of time (Emerson 1998; Reid 2011; Walters et al. 2014). However it was also clear that contemplation and/or prayer does not align absolutely with the concept of flow and the relationship is complex. Diaz (2013) discusses the earlier work of psychologists Csikszentmihalyi (1997) and Maslow (1968), particularly highlighting the role of heightened affective experiences within a 'flow' state, but also asserts that flow can only be experienced when basic survival and safety needs are not threatened. This is not the case with prayer. A threat to safety personal, community or even global, may precipitate the need to pray (Roberts et al. 2009).

As discussed above, practice measured against a set of defined rules, aligns with Hocking's (2009) assertion that we need to understand the rules of an activity and who is making and interpreting those rules. However it was clear, from the data here, that while rules are important so is the concept of individualised practice that meets a much more personal need. This is a key consideration within the health and social care context where an objective is to provide person centred care (Waters and Buchanan 2017). An understanding of the 'accepted' structure of a person's faith may be far removed from their own personal practice and needs. The 'psychology of religion' has also identified a complex relationship between the personal and the 'public' expressions of religion. McGuire (2008) identified that 'a person's religion is not a miniature copy of their group's official religion' (p. 6). Individual variation, a personal perception of practice, must form part of the composite description of religious practice as this too featured clearly in the data. This understanding is important for occupational therapists, to ensure person centred goals shape their intervention and to enable a more confident inclusion of individual differences.

Expressions of practice also link to the concept of occupational identity (Kielhofner 2008; Phelan and Kinsella 2009), which is seen as a complex, dynamic state that evolves and changes over time. This is supported within the narratives here with some participants expressing their practice in terms of a story recalling their religious doing as it has developed and evolved over time. This is also important for occupational therapists, who need to consider that religious doing may change and develop as their clients grow in autonomy and occupational freedom. One's religion is far from a static construct and can be influenced by numerous factors. The data here confirms the concept of faith development over the life course (Fowler 2004), the possibility that prejudice and social factors (Stewart et al. 2018) influence doing and that varying levels of connectedness are experienced (Creek and Cook 2017). All of these play significant roles in the everyday lived experience of people of faith.

Connectedness was discussed as one of the most meaningful aspects of practice with participants talking about numerous levels of belonging. This was expressed as belonging to a group of other worshippers/practitioners and, in addition, to previous generations of practitioners. Being part of a continuum of practice that extends beyond their own existence, and being part of a tradition that they felt it was important to continue. Occupational science has offered numerous insights into the importance of cultural tradition (Hocking et al. 2002; Bonder 2007; Wright-St Clair and Nayar 2017) and for occupational therapists the importance of opportunity to participate, attitudes towards participation and even issues of prejudice or marginalisation are not new challenges in relation to the practice of 
cultural tradition. Hence should the question be asked, are they not also acceptable challenges in the area of religious tradition or doing?

Worldviews were expressed by participants as constructed from their religious beliefs. Several stated that their belief systems gave them a specific way of looking at the world and strength in dealing with the world around them. This is reflected in literature concerning religious coping (Pargament et al. 2000) which is prevalent in the 'psychology of religion' literature but has not, to our knowledge, been seen in occupational therapy literature. The use of photographs has given the added opportunity to glimpse the worldview of the participants.

It was also interesting that non-Christian participants felt the need to position their practice within a Christian understanding. Many explained aspects of their practice using perceived similarities between their practice and what they understood Christians might do. This may mean that the reflective description of religious practice offered here, needs to be defined as relating to the UK, as this description may be articulated differently if the study presented here were conducted in another country or culture.

Reflection on the data indicates that terms such as religion and faith and to a lesser degree spirituality were used interchangeably by participants, and aspects of doing were placed in all three categories. This suggests that the boundaries between religion, spirituality and faith (McGuire 2008) may not be significant distinctions when the objective is a person centred understanding of the occupation of religious doing. Here there was an individual and variable use of the terms and this may suggest that academic argument, related to what is spirituality and what is religion, is unhelpful when trying to illuminate and understand everyday 'lived' practice. The study reported here supports the view that religious doing is likely to be multi-dimensional, diverse, individual, adaptable and malleable, or even 'messy' (McGuire 2008).

The themes were separated into descriptive or more outward facing practice and then more inward facing meaning-laden practice. This has also been described as the 'horizontal and vertical' aspects of spirituality (Schulz 2004; Johnson and Mayers 2005), where the vertical axis relates to inward personal concepts of faith and the horizontal axis relates to outward facing practice. Applying this concept to religious doing, it may be argued that occupational therapists struggle with religious practice as an occupation because they focus their attention on the vertical axis, i.e., more related to theological doctrine and extremely personal held faith. Whereas a focus on religious doing, i.e., the horizontal axis, would enable a greater focus on the practical needs of clients and the use of occupational therapy core skills, such as activity analysis (Thomas 2011). A shift of focus in this way would enable occupational therapists who currently feel ill-equipped to deal with religious doing, to realise that they already have the practice skills and tools to work with problems of religious doing in the same way that they use these tools when working with problems of personal care, social interaction or employment.

\section{Summary and Conclusions}

In summary, in line with the Reflective Lifeworld approach to analysis, a reflective description of religious doing within the everyday lives of the participants is offered below, which has been generated from analysis of the data obtained in the study reported here.

Religious practice involves familiarity of ritual and celebration, activities that re-affirm doctrine and beliefs and link to one's worldview. There is comfort in participation in a range of habitual practices, which may be personalised within a broader, accepted structure.

Religious practice involves contemplation of, and a connectedness with, the divine or the other. Requiring time and space and also facilitating time and space within sometimes busy lives.

Religious practice is part of a developing process, we grow within our religious needs and expressions across our lifecourse. Religious practice is ever changing, adapting and growing. 
Religious practice involves participation with others, a collective and frequently community activity. A sense of belonging to both a local faith family or community, but also a sense of belonging to a more global group and a group spanning past and future generations.

The objective in the study reproted here was to explore the practical religious doing of people from a range of faith traditions, and construct a 'lived' reflective description of their religious doing. No attempt has been made to explore philosophy or theology in relation to the various religions practiced by the participants. In everyday life theology will, of course, have relevance on a fundamental level but the focus here is on understanding the everyday lived experience of the participants, and as such to take a focussed view of their occupational performance, from a practical 'doing' perspective. In terms of practical theology, there has been a very clear focus on the 'practical' as opposed to the 'theology'. There is of course scope for further work examining individual activities within different faith traditions and linking theological concepts with 'doing' i.e., ablutions before prayer or participation in Holy Communion, however the intention here is to reflect on the core issues of doing across faiths, as experienced by the participants.

The reluctance of many occupational therapists to include religious doing in their interventions would seem to be a persistent issue and while successive surveys have shown that practitioners can see that religious doing may be important to their clients (Thompson et al. 2018), they continue to find this area of 'doing' extremely challenging. The study reported here was undertaken with the intention to illuminate the importance of the things people do as part of their religious practice, and enable a better understanding of the meaning and importance of these everyday practices especially if and when barriers to participation arise. As a practicing Christian, I (PE) would not be content with therapy that did not include this most significant and valued occupation, should I ever need the services of an occupational therapist. The reflective description of religious practice (or doing) offered here suggests there are core aspects of doing that are seen across the faiths/traditions of the participants. While, in keeping with phenomenological principles, the findings here are not generalizable beyond these participants, it is hoped that transferable insights and an empathetic understanding of the experiences of the people represented here will resonate with occupational therapists and encourage a reflective examination of their practice with people in similar circumstances. This is suggested as a starting point for practitioners, that does not require an in-depth knowledge of a specific religion but rather an understanding of key and familiar occupational principles such as performance analysis, person-centred habits and routines, and community connectedness. As therapists, we need to understand our clients and how they take part in and form their part of the world. As Rudman (2012) states 'A comprehensive understanding of how occupations are shaped, negotiated, and experienced is needed' (p. 111). On this basis, is it enough to explore mobility needs, but not address a person's inability to prostrate in prayer? Is it enough to consider fine motor skills in relation to activities of daily living, but not discuss difficulties holding a rosary? Is it good enough to work on social anxiety without considering difficulties attending the synagogue? These are just a few of the very many possible ways that religious doing could offer tasks and activities not only helpful to the therapeutic repertoire but essentially relevant to health and wellbeing for many clients/patients.

Author Contributions: Conceptualization, P.E.; Formal analysis, P.E.; Investigation, P.E.; Supervision, K.B. and G.L.; Writing-original draft, P.E.

Funding: This research received no external funding.

Acknowledgments: Support from the School of Health Professions, University of Plymouth who have funded the $\mathrm{PhD}$ of the first author. The PenCLAHRC Evidence Synthesis Team (EST), Elizabeth Casson Trust, Gladstone's Library Scholarship Fund.

Conflicts of Interest: There are no conflicts of interest. 


\section{References}

Beagan, Brenda L., and Josephine B. Etowa. 2011. The meanings and functions of Occupations related to Spirituality for African Nova Scotian Women. Journal of Occupational Science 18: 210-22. [CrossRef]

Blackman, Anna. 2007. The Photovoice Manual: A Guide to Designing and Running Participatory Photography Projects. London: PhotoVoice.

Bonder, Bette R. 2007. An occupational perspective on cultural evolution. Journal of Occupational Science 14: 16-20. [CrossRef]

Braun, Virginia, and Victoria Clark. 2006. Using Thematic analysis in psychology. Qualitative Research in Psychology 3: 77-101. [CrossRef]

Bursell, Jennifer, and Christine A. Mayers. 2010. Spirituality within dementia care: Perceptions of health Professionals. British Journal of Occupational Therapy 73: 144-51. [CrossRef]

Catalani, Caricia, and Meredith Minkler. 2010. Photovoice: A Review of the Literature in Health and Public Health. Health Education and Behaviour 37: 424-51. [CrossRef] [PubMed]

Courtney, Michelle. 2013. A Review of the literature exploring the occupation of contemporary pilgrimage. Journal of Occupational Science 22: 170-82. [CrossRef]

Creek, Jennifer, and Sarah Cook. 2017. Learning from the margins: Enabling effective Occupational Therapy. British Journal of Occupational Therapy 80: 423-31. [CrossRef]

Csikszentmihalyi, Mihalyi. 1997. Creativity: Flow and the Psychology of Discovery and Invention. New York: Harper Collins.

Dahlberg, Karin. 2006. The essence of essences/the search for meaning structures in phenomenological analysis of lifeworld phenomena. International Journal of Qualitative Studies on Health and Well-Being 1: 11-19. [CrossRef]

Dahlberg, Helena, and Karin Dahlberg. 2019. Open and Reflective Lifeworld Research: A Third way. Qualitative Inquiry, 1-7. [CrossRef]

Darnell, Regna. 2002. Occupation is not a Cross-Cultural Universal: Some reflections from an Ethnographer. Journal of Occupational Science 9: 5-11. [CrossRef]

Diaz, Frank M. 2013. Mindfulness, attention and flow during music listening: An empirical Investigation. Psychology of Music 41: 42-58. [CrossRef]

Emerson, Heather. 1998. Flow and Occupation: A review of the literature. Canadian Journal of Occupational Therapy 65: 37-44. [CrossRef]

Farah, Jennifer, and Mary Ann McColl. 2008. Exploring Prayer as a Spiritual modality. Canadian Journal of Occupational Therapy 75: 5-13. [CrossRef]

Finlay, Linda. 2011. Phenomenology for Therapists: Researching the lived World. Chichester: Wiley-Blackwell.

Fisher, Anne G. 2013. Occupation-centred, occupation-based, occupation-focussed: Same, same or different? Scandinavian Journal of Occupational Therapy 20: 162-73. [CrossRef]

Fowler, James W. 2004. Faith Development at 30: Naming the Challenges of Faith in a new millennium. Religious Education 99: 405-21. [CrossRef]

Gray, David E. 2004. Doing Research in the Real World. London: Sage Publications.

Guest, Greg, Kathleen M. MacQueen, and Emily E. Namey. 2012. Applied Thematic Analysis. London: Sage.

Hartman, Angea Mandich, Lilian Magalhães, and Treena Orchard. 2011. How do we 'see' Occupations? An examination of Visual Research Methodologies in the study of Human Occupation. Journal of Occupational Science 18: 292-305. [CrossRef]

Hocking, Clare. 2009. The challenge of occupation: Describing the things people do. Journal of Occupational Science 16: 140-50. [CrossRef]

Hocking, Clare, Valerie Wright-St Clair, and Wannipa Bunrayong. 2002. The meaning of cooking and recipe work for older Thai and New Zealand women. Journal of Occupational Science 9: 117-27. [CrossRef]

Iwama, Michael. 2003. Toward culturally relevant epistemologies in occupational therapy. American Journal of Occupational Therapy 57: 582-88. [CrossRef]

Johnson, Diane, and Christine Mayers. 2005. Spirituality: A Review of How Occupational Therapists Acknowledge, Assess and Meet Spiritual Needs. British Journal of Occupational Therapy 68: 386-92. [CrossRef]

Jones, Andrea SunMee. 2004. What the doing does: Religious Practice and the problem of meaning. Journal of Cultural Religious Theory 6: 86-107. 
Kielhofner, Gary. 2008. Model of Human Occupation: Theory and Application. Baltimore: Lippincott, Williams and Wilkins.

Koenig, Harold G. 2011. Spirituality and Health Research: Methods, Measurement, Statistics and Resources. West Conshohocken: Templeton Press.

Lal, Shalini, Tal Jarus, and Melinda J. Suto. 2012. A scoping review of the Photovoice method: Implications for occupational therapy research. Canadian Journal of Occupational Therapy 79: 181-90. [CrossRef] [PubMed]

Letherby, Gayle, John Scott, and Malcolm Williams. 2013. Objectivity and Subjectivity in Social Research. London: Sage Publications Ltd.

Rudman, Debbie Laliberte. 2012. Governing through occupation: Shaping expectations and possibilities. In Occupational Science: Society, Inclusion, Participation. Edited by Gail E. Whiteford and Clare Hocking. Oxford: Blackwell Publishing Ltd., pp. 100-16.

Maslow, Abraham H. 1968. Towards a Psychology of Being, 2nd ed.New York: Van Nostrand Reinhold.

Mason, Jennifer. 2011. Facet Methodology: The case for an inventive research orientation. Methodological Innovations Online 6: 75-92. [CrossRef]

Mason, Jennifer, and Katherine Davies. 2009. Coming to our senses? A critical approach to sensory methodology. Qualitative Research 9: 587-603. [CrossRef]

McGuire, Meredith B. 2008. Lived Religion: Faith Practice in Everyday Life. Oxford: Oxford University Press.

Nowell, Lorelli S., Jill M. Norris, Deborah E. White, and Nancy J. Moules. 2017. Thematic Analysis: Striving to Meet the Trustworthiness Criteria. International Journal of Qualitative Methods 16: 1-13. [CrossRef]

Odawara, Etsuko. 2005. Cultural Competency in Occupational Therapy: Beyond a Cross-Cultural View of Practice. American Journal of Occupational Therapy 59: 325-34. [CrossRef] [PubMed]

Pargament, Kenneth I., Harold G. Koenig, and Lisa M. Perez. 2000. The many methods of religious coping: Development and initial validation of the RCOPE. Journal of Clinical Psychology 56: 519-43. [CrossRef]

Phelan, Shanon, and Elizabeth Anne Kinsella. 2009. Occupational Identity: Engaging socio-cultural perspectives. Journal of Occupational Science 16: 85-91. [CrossRef]

Pew Research Center. 2015. The Future of World Religions: Population Growth Projections, 2010-2050. Available online: http://www.pewforum.org/2015/04/02/religious-projections-2010-2050/ (accessed on 21 January 2019).

Pickens, Noralyn Davel, and Kris Pizur-Barnekow. 2009. Co-occupation: Extending the dialogue. Journal of Occupational Science 16: 151-56. [CrossRef]

Reid, Denise. 2011. Mindfulness and Flow in occupational engagement: Presence in doing. Canadian Journal of Occupational Therapy 78: 50-56. [CrossRef]

Roberts, Leanne, Irshad Ahmed, and Andrew Davison. 2009. Intercessory Prayer for the Alleviation of Ill-Health (REVIEW). Hoboken: The Cochrane Collaboration Wiley and Sons. [CrossRef]

Schulz, Emily. 2004. Spirituality and disability: An analysis of selected themes. Occupational Therapy in Health Care 18: 57-83. [CrossRef] [PubMed]

Schuurmans-Stekhoven, James. 2019. Auspicious or suspicious-Does religiosity really promote elder well-being? Examining the belief-as-benefit effect among older Japanese. Archives of Gerontology and Geriatrics 81: 129-135. [CrossRef] [PubMed]

Smith-Gabai, Helene, and Ferol Ludwig. 2011. Observing the Jewish Sabbath: A Meaningful Restorative Ritual for Modern Times. Journal of Occupational Science 18: 347-55. [CrossRef]

Smith, Sharon, and Melinda J. Suto. 2012. Religious and/or Spiritual Practices: Extending Spiritual Freedom to People with Schizophrenia. Canadian Journal of Occupational Therapy 79: 77-85. [CrossRef] [PubMed]

Stewart, Evan, Penny Edgell, and Jack Delehanty. 2018. The Politics of Religious Prejudice and Tolerance for cultural others. The Sociological Quarterly 59: 17-39. [CrossRef]

Swinton, John, and Stephen Pattison. 2010. Moving beyond clarity: Toward a thin, vague, and useful understanding of spirituality in nursing care. Nursing Philosophy 11: 226-37. [CrossRef]

Thomas, Heather. 2011. Occupation-based Activity Analysis. Thorofare: Slack.

Thompson, Kelly, Bryan M. Gee, and Sara Hartje. 2018. Use of Religious Observance as a Meaningful Occupation in Occupational Therapy. Open Journal of Occupational Therapy (OJOT) 6: 1-19. [CrossRef]

Tufford, Lea, and Peter Newman. 2010. Bracketing in Qualitative Research. Qualitative Social Work 11: 80-96. [CrossRef]

Unruh, Anita M., Joan Versnel, and Natasha Kerr. 2002. Spirituality Unplugged: A Review of Commonalities and Contentions, and a Resolution. Canadian Journal of Occupational Therapy 69: 5-19. [CrossRef] 
Van Manen, Max, Isabel Higgins, and Pamela van der Riet. 2016. A conversation with Max van Manen on phenomenology in its original sense. Nursing and Health Sciences 18: 4-7. [CrossRef]

Wang, Caroline, and Mary Ann Burris. 1997. Photovoice: Concept, Methodology, and Use for Participatory Needs Assessment. Health Education and Behaviour 24: 369-87. [CrossRef]

Walters, Julie, Wendy Sherwood, and Helen Mason. 2014. Creative Activities in Creeks Occupational Therapy and Mental Health. Edited by Wendy Bryant, Jon Fieldhouse and Katrina Bannigan. London: Churchill Livingstone, pp. 260-76.

Warren, Samantha. 2005. Photography and voice in critical qualitative management research. Accounting, Auditing and Accountability Journal 18: 861-82. [CrossRef]

Waters, Rebecca A., and Angus Buchanan. 2017. An exploration of person-centred concepts in human services: A thematic analysis of the literature. Health Policy 121: 1031-39. [CrossRef]

Wilcock, Ann Allart. 1999. Reflections on doing, being and becoming. Australian Occupational Therapy Journal 46: 1-11. [CrossRef]

Wilcock, Ann A. 2007. Occupation and health: Are They One and the Same? Journal of Occupational Science 14: 3-8. [CrossRef]

Wilding, Clare, Esther May, and Eimear Muir-Cochrane. 2005. Experience of spirituality, mental-illness and occupation: A Life-sustaining phenomenon. Australian Occupational Therapy Journal 52: 2-9. [CrossRef]

Wright-St Clair, Valerie A., and Shoba Nayar. 2017. Older Asian immigrants' participation as cultural enfranchisement. Journal of Occupational Science 24: 64-75. [CrossRef]

(C) 2019 by the authors. Licensee MDPI, Basel, Switzerland. This article is an open access article distributed under the terms and conditions of the Creative Commons Attribution (CC BY) license (http://creativecommons.org/licenses/by/4.0/). 